\title{
Perencanaan Strategis SI/TI Perusahaan Manufaktur Dengan Analisa SWOT: Studi Kasus PT. TBP Jakarta
}

\author{
Siswidiyanto \\ UNIVERSITAS BINA SARANA INFORMATIKA \\ e-mail: siswidiyanto.sid@bsi.ac.id
}

Cara Sitasi: Siswidiyanto. (2019, Maret). Perencanaan Strategis SI/TI Perusahaan Manufaktur Dengan Analisa SWOT: Studi Kasus PT. TBP Jakarta. (S. Dalis, Ed.) Paradigma - Jurnal Komputer dan Informatika, 21(1), 107112. doi:10.31294/p.v21i1.5123

\begin{abstract}
In order to win the business competition in the world today, every company must have a special strategy. One company that is very strict business competition is the manufacturing industry. Similar products from a manufacturing industry at this time is very much because of manufacturing companies grow rapidly. In its development only companies capable of competing alone who will be able to face these challenges. In the manufacturing industry the need for information about the processes that occur need to be done SI / IT planning is right so that will give a significant impact on the condition of the company to achieve business goals. For that writer trying to make strategic planning in industry manufacture, especially at PT. Trimitra Battery Prakasa(TBP). In this research, the researcher uses IS / IT strategic planning methodology as the basic concept of strategic planning model using Tozer method application based on business strategy. Analysis and interpretation of research data using SWOT method. Where this method will strengthen the preparation of strategic planning. The end result of this research is strategic planning of SI / IT which includes identifying details of problem handling steps and identification of future development of IT / IT which is described in the form of SI / IT portfolio which is in line with business strategy of PT Trimitra Battery Prakasa(TBP). in order to create competitive advantage in order to compete.
\end{abstract}

Keywords: Perencanaan strategis, SWOT, perusahaan manufaktur, sistem informasi dan teknologi.

\section{PENDAHULUAN}

Perkembangan teknologi informasi pada saat ini sangatlah pesat sehingga banyak perusahaan menjadikan teknologi informasi sebagai daya saing dalam perusahaannya untuk memenangkan persaingan bisnis yang semakin lama semakin ketat dalam perkembangan ekonomi global. .

Sistem Informasi dan Teknologi Informasi tersebut berdampak positif terhadap berbagai aktivitas bisnis di dalam perusahaan, maupun aktivitas bisnis dengan pihak luar perusahaan. Dampak positif yang dimaksud adalah sangat dimungkinkan terjadinya percepatan dan peningkatan akurasi informasi sehingga tercipta nilai-nilai efisiensi dan efektivitas yang sangat dibutuhkan oleh perusahaan.

Perencanaan strategis sistem informasi merupakan pendekatan sistematis mengenai apa yang dianggap paling efektif dan efisien untuk memenuhi kebutuhan informasi.Pendekatan perencanaan strategis system informasi yang dikemukakan oleh TOZER yang mendasari penelitian ini menggunakan metode analisis SWOT.

Sasaran utama yang akan dicapai dari upaya penerapan SI/TI dalam suatu organisasi, yaitu: Pertama, memperbaiki efisiensi kerja dan efektifitas kerja dengan melakukan otomasi berbagai proses yang mengelola informasi; Kedua, meningkatkan kemudahan pihak manajemen akan kebutuhan informasi untuk pengambilan keputusan yang tepat dalam perencanaan bisnisnya; dan Ketiga, memperbaiki daya saing atau meningkatkan keunggulan kompetitif organisasi dengan merubah gaya dan cara berbisnis (Ward \& Peppard, 2016)

Tujuan dilakukannya penelitian ini adalah berfokus pada memberikan solusi terhadap permasalahan yang dihadapai oleh PT. Trimitra Baterai Prakasa. Melalui penyusunan rencana strategic system informasi meliputi: mengidentifikasi penerapan system informasi yang sedang berjalan di dalam perusahaan, dan menganalisis kebutuhan penerapan system informasi perusahaan di masa yang akan datang.

\section{Latar Belakang}


Persaingan bisnis yang terjadi saat ini sangatlah ketat, baik dalam industri barang maupun dalam industri jasa. Hal ini terjadi karena semakin banyaknya industri barang dan jasa yang tumbuh diberbagai bidang dan diberbagai negara. Kondisi persaingan ini juga dipicu adanya kawasan-kawasan ekonomi eklusif diberbagai belahan dunia seperti kawasan ekonomi ASEAN. Dengan demikian hanya perusahaan-perusahaan yang mempunyai efektifitas dan efisiensi yang tinggi yang akan bisa bersaing dan bertumbuh.

Dalam pengolahan data setiap harinya PT. Trimitra Baterai Prakasa masih menggunakan sistem data yang konvensional dimana data tersebut terpisah-pisah antara data satu departemen dengan departemen yang lainnya. Belum lagi masih banyak data yang belum dilakukan pengolahan data secara komputerisasi.

Pengolahan data setiap departemen juga menggunakan sistem aplikasi yang berbeda-beda. Sehingga data yang dihasilkan harus dilakukan analisa ulang untuk mendapatkan informasi yang sesuai dengan kebutuhan dari manajemen. Untuk menunjang hal tersebut manajemen masih memerlukan usaha yang lebih sehingga hal ini kurang efektif dan kurang efisien dalam perkembangan perusahaan yang begitu cepat. Dimana dengan perkembangan perusahaan seperti tersebut, kebutuhan akan ketepatan dan kecepatan data untuk menghasilkan informasi yang baik dan sesuai dengan kebutuhan manajemen harus segera dipenuhi. Hal ini memerlukan suatu perencenaan sistem informasi dan teknologi informasi yang memadai.

Dengan pemenuhan kebutuhan sistem informasi dan teknologi informasi yang memadai diharapkan akan dapat memberikan dampak yang lebih baik terhadap perkembangan perusahaan.

\section{Rumusan Permasalahan}

Perusahaan manufaktur atau perusahaan yang menghasil barang jadi maupun barang setengah jadi yang sedang berkembang pada saat ini sudah banyak yang memiliki perencanaan strategis Sistem Informasi / Teknologi Informasi untuk memenangkan persaingan bisninya, akan tetapi masih ada juga perusahaan yang belum memiliki perencanaan strategis Sistem Informasi / Teknologi Informasi sehingga masih perlu adanya perumusan strategis Sistem Informasi / Teknologi Informasi. Rumusan masalah pada penulisan ini adalah “ Bagaiman membangun strategis Sistem Informasi / Teknologi Informasi pada PT. Trimitra Baterai Prakasa agar tujuan bisnisnya tercapai”.

\section{Tujuan Penelitian}

Penelitian yang dilakukan oleh penulis ini bertujuan untuk menghasilkan bentuk usulan pengembangan Sistem Informasi / Teknologi Informasi pada PT. Trimitra Baterai Prakasa agar dapat mendukung strategi perusahaan dalam rangka menghadapi persaingan pasar yang sangat ketat. Serta dapat mendukung terwujudnya visi dan misi dari PT. Trimitra Baterai Prakasa.

\section{Manfaat Penelitian}

Hasil penelitian yang berupa model strategi SI/TI pada PT. Trimitra Baterai Prakasa ini, diharapkan bermanfaat bagi sebuah referensi untuk memandu upaya pemanfaatan dan pengelolaan Sistem Informasi / Teknologi Informasi yang sesuai dengan kebutuhan perusahaan. Diharapkan juga penelitian ini bermanfaat untuk menambah referensi dan memperkaya pengetahuan di bidang perencanaan strategis Sistem Informasi / Teknologi Informasi.

\section{METODOLOGI PENELITIAN}

Pada dasarnya konsep perencanaan strategis ini adalah visi, misi, serta tujuan bisnis organisasi yang mengarahkan Sistem Informasi / Teknologi Informasi. Walaupun dalam proses perencanaannya akan membutuhkan waktu dan tenaga untuk mempertajam perencanaan bisnis sebelum melangkah pada perencanaan Sistem Informasi / Teknologi Informasi.

Berikut ini kerangka kerja yang penulis lakukan dalam menentukan rencana strategis Sistem Informasi / Teknologi Informasi di PT. Trimitra Baterai Prakasa.
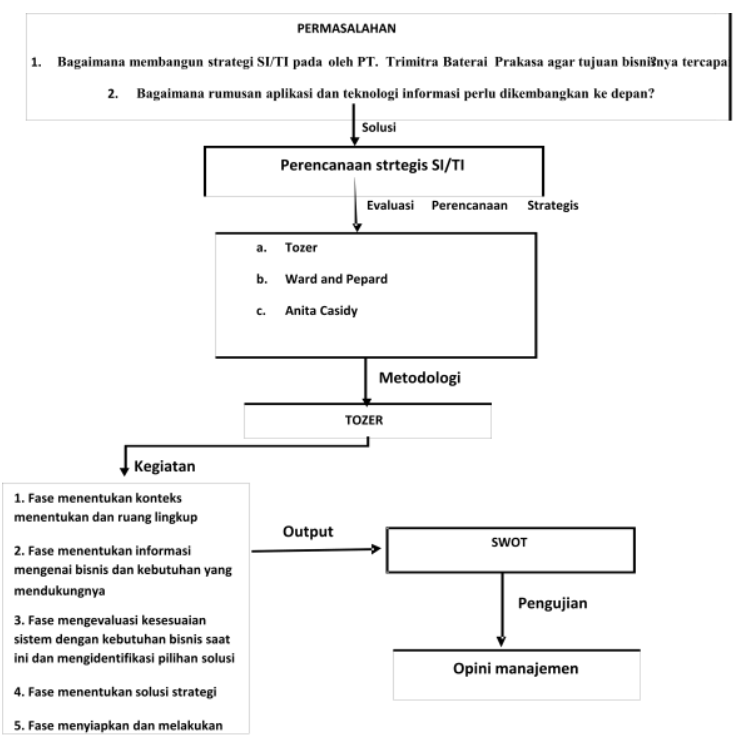

Gambar 1 . Pembuatan kerangka kerja perencanaan strategis Sistem Informasi / Teknologi Informasi

Kerangka kerja perencanaan strategis Sistem Informasi / Teknologi Informasi yang berupa kerangka standar kegiatan dalam menyusun 
perencanaan strategis Sistem Informasi / Teknologi Informasi yang dilengkapi dengan langkah-langkah penyusunannya yang dilakukan dalam beberapa fase sebagai berikut:

1. Fase pertama, menentukan konteks dan ruang lingkup.

Penjelasan pada fase ini akan diperoleh mengenai batasan, waktu kontrol, penyelarasan terminologi, komitmen manajemen dan harapan dari sistem yang akan dibangun atau dikembangkan. Keluaran yang dihasilkan pada fase ini adalah analisa konteks, batasannya, identifikasi pendahuluan, tim kerja, dan program kerja.

2. Fase kedua, menentukan informasi mengenai bisnis dan kebutuhan yang mendukungnya.

Dalam fase ini akan dicari dasar dasar untuk membuat strategi yang berupa rencana ke depan dalam bentuk rencana bisnis dan informasi pendukung lainnya. Dalam fase ini dibagi menjadi dua kegiatan yaitu persiapan pengumpulan informasi dan menentukan informasi bisnis dan pendukungnya.

3. Fase ketiga, mengevaluasi kesesuaian sistem dengan kebutuhan bisnis saat ini dan mengidentifikasi pilihan solusi.

Penjelasan dalam fase ini meliputi empat kegiatan yaitu evaluasi aplikasi dan kondisi teknis pada saat ini, membangun infrastruktur informasi, membuat pilihan awal untuk solusi strategis, dan membangun kasus bisnis untuk memenuhi kebuttuhan bisnis yang sedang dijalankan.

4. Fase ke empat, menentukan solusi strategi. Dalam fase ini terdapat empat kegiatan yaitu mengidentifikasi dan memulai kegiatan yang mendesak, menentukan solusi aplikasi dan database, menevaluasi kondisi Teknologi Informasi, dan mengembangkan kasus bisnis.

5. Fase ke lima, menyiapkan dan melakukan rencana implementasi. Pada fase ini akan diselesaikan dan dilaksanakan perencanaan strategis Sistem Informasi / Teknologi Informasi, dimana terdapat beberapa kegiatan yang harus dilakukan antara lain menyiapkan rencana teknis proyek aplikasi dan database, mempersiapkan rencana pengembangan Sumber Daya Manusia dan organisasi, menyusun dan menyeimbangkan kasus-kasus bisnis dengan semua pengembangan, serta mengatur rencana dan mengatur implementasinya

\section{HASIL DAN PEMBAHASAN}

Analisa yang akan penulis lakukan adalah analisa mengenai proses bisnis yang terjadi dan teknologi informasi yang akan dilakukan mencakup mengevaluasi kesesuaian sistem dengan kebutuhan bisnis saat ini dan menentukan solusi strategi yang dapat meningkatkan efisiensi dan efektifitas pada PT. Trimitra Baterai Prakasa.

Analisa dititikberatkan pada evaluasi kondisi perusahaan saat ini dan menentukan solusi strategis untuk masa depan perusahaan. Sebagai perangkat dan metode analisa digunakan adalah analisa SWOT.

\section{Analisis SWOT}

\section{Identifikasi Kekuatan}

Berdasarkan hasil yang diperoleh maka factor kekuatan yang dimiliki oleh PT. Trimitra Baterai Prakasa adalah :
a) Pangsa pasar di seluruh dunia
b) Sistem pemasaran international
c) Mempunyai unit-unit proses produksi yang tidak dimiliki oleh perusahaan pesaing yang sejenis
d) Sudah menerapkan sistem ISO9001 dan ISO14000
e) Didukung oleh teknologi terkini dalam proses produksi
f) Didukung oleh staff ahli langsung dari jepang
g) Terdapat kurang lebih 300 unit komputer
h) Semua komputer sudah terkoneksi dalam LAN
i) Sistem data sudah tersentralisasi dalam server

\section{Identifikasi Kelemahan}

Berdasarkan hasil yang diperoleh maka factor kelemahan yang dimiliki oleh PT. Trimitra Baterai Prakasa adalah :
a) Belum dilakukan sistem komplain dari konsumen secara real time
b) Masih ditemukannya beberapa produk yang gagal fungsi pada konsumen
c) Sistem data tiap departemen belum terintegrasi
d) Belum adanya penerapan knowledge manajemen dengan baik

\section{Identifikasi Peluang}

Berdasarkan hasil yang diperoleh maka factor peluang yang dimiliki oleh PT. Trimitra Baterai Prakasa adalah :
a) Peraturan pemerintah yang membuka lebar untuk sistem informasi dan tekonologi informasi yang dipakai pada masyarakat
b) Perkembangan teknologi informasi yang begitu cepat
c) Semakin banyaknya pemakai kendaraan bermotor roda empat di Indonesia 
d) Semakin banyaknya jenis kendaraan bermotor roda empat yang masuk pasar indonesia khususnya dan dunia pada umumnya

\section{Identifikasi Ancaman}

Berdasarkan hasil yang diperoleh maka faktor ancaman yang harus dihadapi oleh PT. Trimitra Baterai Prakasa adalah sebagai berikut:

a) Semakin banyaknya perusahaan pesaing yang membuat produk yang sama

b) Lebih bervariasinya merek produk yang ada di pasaran

c) Semakin banyaknya produk import yang masuk ke indonesia

Berikut ini hasil analisa SWOT mengenai apa yang harus dilakukan oleh PT. Trimitra Baterai Prakasa untuk menghadapi tantangan di masa depan yang berhubungan dengan SI/TI perusahaan untuk mencapai tujuan bisnis dari perusahaan tersebut .

Tabel 1. Tabel analisa SWOT pada PT. Trimitra Baterai Prakasa

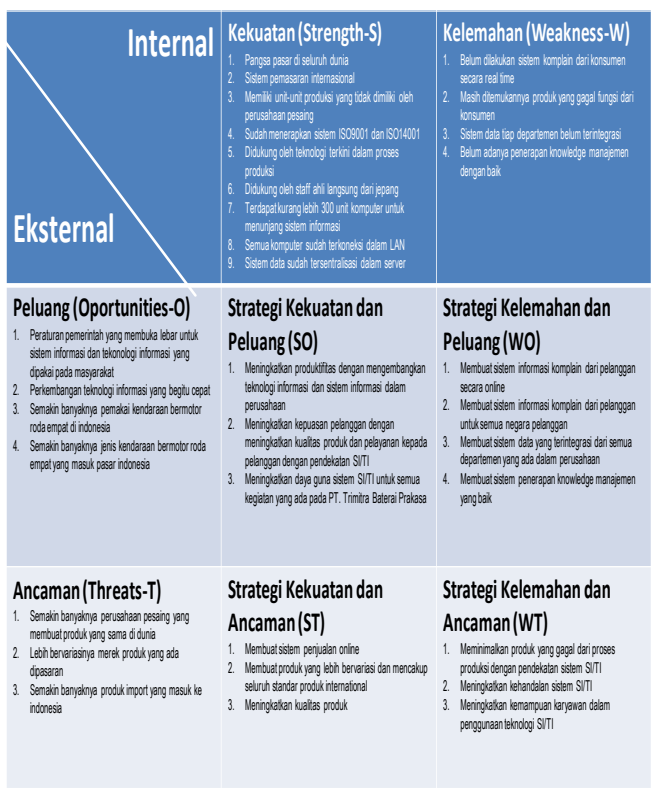

Tabel 2. Tabel pembobotan faktor kekuatan internal pada PT. Trimitra Baterai Prakasa

\begin{tabular}{llllll}
\hline No & \multicolumn{1}{c}{ Kekuatan } & \multicolumn{2}{c}{ Rata-rata } & Skor \\
\cline { 3 - 4 } & & Bobot & Rating & \\
\hline 1 & $\begin{array}{l}\text { Pangsa pasar di } \\
\text { seluruh dunia }\end{array}$ & 0,099 & 3,6 & 0,358 \\
\hline 2 & $\begin{array}{l}\text { Sistem pemasaran } \\
\text { international }\end{array}$ & 0,097 & 3,7 & 0,358
\end{tabular}

\begin{tabular}{|c|c|c|c|c|}
\hline 3 & $\begin{array}{l}\text { Mempunyai unit- } \\
\text { unit proses produksi } \\
\text { yang tidak dimiliki } \\
\text { oleh perusahaan } \\
\text { pesaing yang sejenis }\end{array}$ & 0,097 & 3,2 & 0,309 \\
\hline 4 & $\begin{array}{l}\text { Sudah menerapkan } \\
\text { sistem ISO9001 dan } \\
\text { ISO14000 }\end{array}$ & 0,083 & 2,2 & 0,182 \\
\hline 5 & $\begin{array}{lr}\text { Didukung } & \text { oleh } \\
\text { teknologi } & \text { terkini } \\
\text { dalam } & \text { proses } \\
\text { produksi } & \end{array}$ & 0,097 & 3,2 & 0,309 \\
\hline 6 & $\begin{array}{l}\text { Didukung oleh staff } \\
\text { ahli langsung dari } \\
\text { jepang }\end{array}$ & 0,099 & 3,9 & 0,388 \\
\hline 7 & $\begin{array}{lr}\text { Terdapat } & \text { kurang } \\
\text { lebih } 300 \quad \text { unit } \\
\text { komputer }\end{array}$ & 0,088 & 3,3 & 0,292 \\
\hline 8 & $\begin{array}{lr}\begin{array}{l}\text { Semua } \\
\text { sudah }\end{array} & \text { komputer } \\
\text { dalam LAN }\end{array}$ & 0,088 & 2,8 & 0,248 \\
\hline 9 & $\begin{array}{l}\text { Sistem data sudah } \\
\text { tersentralisasi dalam } \\
\text { server }\end{array}$ & 0,086 & 2,6 & 0,223 \\
\hline
\end{tabular}

Tabel 3. Tabel pembobotan faktor kelemahan internal pada PT. Trimitra Baterai Prakasa

\begin{tabular}{|c|c|c|c|c|}
\hline \multirow[t]{2}{*}{ No } & \multirow[t]{2}{*}{ Kelemahan } & \multicolumn{2}{|c|}{ Rata-rata } & \multirow[t]{2}{*}{ Skor } \\
\hline & & Bobot & Rating & \\
\hline 1 & $\begin{array}{ll}\text { Belum } & \text { dilakukan } \\
\text { sistem } & \text { komplain } \\
\text { dari } & \text { konsumen } \\
\text { secara real time }\end{array}$ & 0,047 & 2,1 & 0,099 \\
\hline 2 & $\begin{array}{l}\text { Masih } \\
\text { ditemukannya } \\
\text { beberapa produk } \\
\text { yang gagal fungsi } \\
\text { pada konsumen }\end{array}$ & 0,036 & 3,9 & 0,140 \\
\hline 3 & $\begin{array}{l}\text { Sistem data tiap } \\
\text { departemen belum } \\
\text { terintegrasi }\end{array}$ & 0,047 & 2,2 & 0,103 \\
\hline 4 & $\begin{array}{l}\text { Belum adanya } \\
\text { penerapan } \\
\text { knowledge } \\
\text { manajemen dengan } \\
\text { baik }\end{array}$ & 0,036 & 2 & 0,072 \\
\hline
\end{tabular}




\section{TOTAL}

1,000

3,080

Analisis table faktor internal merupakan hasil identifikasi faktor internal PT. Trimitra Baterai Prakasa. Faktor internal tersebut kemudian dibobotkan dan dikelompokkan menjadi faktor kekuatan maupun kelemahan yang dimiliki oleh perusahaan. Setelah dilakukan pembobotan maka dilakukan penilaian terhadap rating masing-masing faktor. Rating yang diperoleh kemudian dikalikan dengan bobot untuk mendapatkan skor masingmasing factor dan hasil keseluruhan skor dijumlahkan. Matriks strategi faktor internal digunakan untuk mengetahui berbagai faktorfaktor strategi internal (kekuatan dan kelemahan) dalam perusahaan sebelum strategi diterapkan.

Tabel 4. Tabel pembobotan faktor eksternal peluang pada PT. Trimitra Baterai Prakasa.

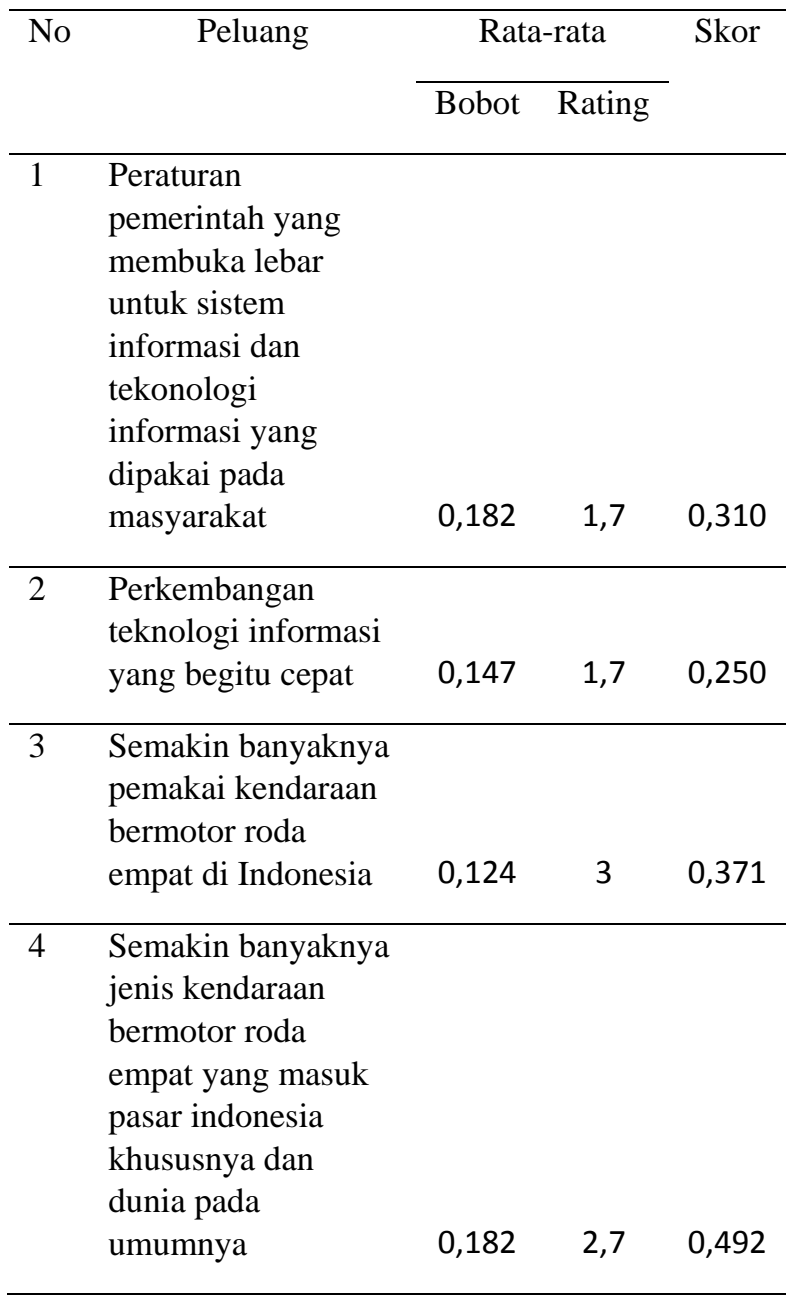

Tabel 5. Tabel pembobotan faktor eksternal ancaman pada PT. Trimitra Baterai Prakasa.

\begin{tabular}{lll}
\hline No Ancaman & \multicolumn{2}{c}{ Rata-rata Skor } \\
& Bobot Rating
\end{tabular}

\begin{tabular}{|c|c|c|c|c|}
\hline 1 & $\begin{array}{l}\text { Semakin banyaknya } \\
\text { perusahaan pesaing } \\
\text { yang membuat } \\
\text { produk yang sama } \\
\text { di dunia }\end{array}$ & 0,124 & 2,2 & 0,272 \\
\hline 2 & $\begin{array}{l}\text { Lebih bervariasinya } \\
\text { merek produk yang } \\
\text { ada dipasaran }\end{array}$ & 0,100 & 2,2 & 0,220 \\
\hline 3 & $\begin{array}{l}\text { Semakin banyaknya } \\
\text { produk import yang } \\
\text { masuk ke indonesia }\end{array}$ & 0,141 & 2,8 & 0,395 \\
\hline & TOTAL & 1,000 & & 2,310 \\
\hline
\end{tabular}

Analisis table faktor eksternal merupakan hasil identifikasi faktor eksternal PT. Trimitra Baterai Prakasa. Faktor eksternal tersebut kemudian dibobotkan dan dikelompokkan menjadi faktor peluang maupun ancaman yang akan dihadapi oleh perusahaan. Setelah dilakukan pembobotan maka dilakukan penilaian terhadap rating masing-masing faktor. Rating yang diperoleh kemudian dikalikan dengan bobot untuk mendapatkan skor masingmasing factor dan hasil keseluruhan skor dijumlahkan. Matriks strategi faktor eksternal digunakan untuk mengetahui berbagai faktorfaktor strategi internal (peluang dan ancaman) dalam perusahaan sebelum strategi diterapkan.

Berdasarkan hasil analisis terhadap faktor internal dan eksternal PT. Trimitra Baterai Prakasa. maka dapat disusun alternatif strategi. Alternatif strategi tersebut disusun melalui matriks SWOT. Analisis SWOT merupakan alat formulasi pengambilan keputusan serta untuk menentukan strategi yang ditempuh berdasarkan kepada logika untuk memaksimalkan kekuatan dan peluang, namun secara bersamaan dapat meminimalkan kelemahan dan ancaman. Hasil dari analisis matriks SWOT adalah adanya delapan alternatif strategi pengembangan, yaitu:

1. Strategi SO adalah strategi yang disusun menggunakan kekuatan untuk memanfaatkan peluang. Strategi SO pada PT. Trimitra Baterai Prakasa. dapat dirumuskan sebagai berikut:

a. Meningkatkan produktifitas dengan mengembangkan teknologi informasi dan sistem informasi dalam perusahaan

b. Meningkatkan kepuasan pelanggan dengan meningkatkan kualitas produk dan pelayanan kepada pelanggan dengan pendekatan SI/TI.

c. Meningkatkan daya guna sistem SI/TI untuk semua kegiatan yang ada pada PT. Trimitra Baterai Prakasa 
2. Strategi WO adalah strategi yang disusun dengan meminimalkan kelemahan untuk memanfaatkan peluang. Strategi WO pada PT. Trimitra Baterai Prakasa. adalah sebagai berikut:

a. Membuat sistem informasi komplain dari pelanggan secara online

b. Membuat sistem informasi komplain dari pelanggan untuk semua negara pelanggan

c. Membuat sistem data yang terintegrasi dari semua departemen yang ada dalam perusahaan

d. Membuat sistem penerapan knowledge manajemen yang baik

3. Strategi ST adalah strategi yang disusun dengan memanfaatkan kekuatan untuk mengatasi ancaman. Strategi ST pada PT. Trimitra Baterai Prakasa adalah sebagai berikut:

a. Membuat sistem penjualan online

b. Membuat produk yang lebih bervariasi dan mencakup seluruh standar produk international

c. Meningkatkan kualitas produk

4. Strategi WT adalah strategi yang disusun dengan meminimalkan kelemahan untuk menghadapi ancaman. Strategi WT pada PT. Trimitra Baterai Prakasa adalah sebagai berikut:

a. Meminimalkan produk yang gagal dari proses produksi dengan pendekatan sistem $\mathrm{SI} / \mathrm{TI}$

b. Meningkatkan kehandalan sistem SI/TI

c. Meningkatkan kemampuan karyawan dalam penggunaan teknologi SI/TI

\section{KESIMPULAN}

Beberapa kesimpulan dan saran yang penulis bisa ambil mengenai Sistem informasi dan yang bisa disampaikan untuk menutup penelitian perencanaan strategis Sistem informsi dengan studi kasus pada PT. Trimitra Baterai Prakasa.

\section{Kesimpulan}

1. Pada perumusan rencana stategis Sistem Informasi /Teknologi Informasi sudah menghasilkan rencana aplikasi system informasi dan teknologi informasi berdasarkan analisa SWOT dari perusahaan tersebut.

2. Dalam implementasi aplikasi yang diusulkan ada beberapa aplikasi yang harus di lakukan pengembangan agar pengembangan bisnis terpenuhi.

\section{Saran}

Dalam proses perencanaan startegis ini masih banyak kekurangan karena masih berupa konseptual sekaligus proses teknis. Pengalaman dalam kegiatan perencanaan akan sangat menunjang proses perencanaan strategis lebih lanjut. Saran-saran yang dapat diberikan dan sekiranya bermanfaat sebagai berikut :

1. Perusahaan agar memperhatikan faktor yang menjadi kekuatan dan kelemahan yang dimilikinya sehingga dapat mencapai peluang dan menghadapi ancaman yang datang dari pihak luar.

2. Keberhasilan dalam menjalankan strategi harus didukung oleh kebijakan perusahaan yang ada serta didukung semua pihak yang terlibat.

3. Penelitian lebih lanjut untuk melengkapi dan menghitung tingkat maturiti suatu rencana strategi SI/TI yang diimplementasikan.

\section{REFERENSI}

Iswara , M.G.Y., dan Sucahyo. Y.G. (2009) Perencanaan Strategis Sistem Informasi Perusahaan Energi : Studi Kasus PT. XYZ, Bali. Proceeding Konferensi Nasioanl Sistem dan Informasi.

Kemas Rahmat SW, M.Eng, Erda Guslinar Perdana (2012) Informatika Fakultas Teknik Universitas Telkom, Perencanaan Strategis Sistem Informasi Menggunakan Metode Ward and Peppard Pada PT. Medika Antapani Satwika Parama Putra.

Andri Wijaya, Dana Indra Sensuse (2011) Perencanaan Strategis Sistem Informasi dan Teknologi Informasi pada perusahaan otomotif dengan menggunakan metodologi Tozer, SNATI, Yogyakarta

Rangkuti, (2005). Analisis SWOT Teknik Membedah Kasus Bisnis, Edisi 12, Jakarta: Gramedia

Tozer , EE, (1996). Strategic IS/IT Planning Profesional series, Butterworth-Heinemann

Sutarman (2009). Pengantar Teknologi Informasi. Jakarta : Sinar Grafika Offset

Ward, J., \& Peppard, J. (2016). The Strategic Palnning for Information System. Strategic Planning for Information Systems. https://doi.org/10.1016/0024-6301(90)90122$\mathrm{K}$

\section{PROFIL PENULIS}

Siswidiyanto, lahir di sleman, Yogyakarta. Saat ini, penulis aktif sebagai dosen di Universitas Bina Sarana Informatika. Menyelesaikan pendidikan Sarjana Komputer dan Magister Ilmu Komputer di STMIK Nusa Mandiri di Jakarta. Penulis mempunyai pengalaman bekerja di industri manufakturing dan sebagai tenaga ahli di sebuah perusahaan sertifikasi produk. 